CLINICAL STUDY

\title{
Treatment of Graves' disease and associated ophthalmopathy with the anti-CD20 monoclonal antibody rituximab: an open study
}

\author{
Mario Salvi, Guia Vannucchi, Irene Campi, Nicola Currò ${ }^{1}$, Davide Dazzi ${ }^{6}$, Simona Simonetta $^{1}$, Paola Bonara ${ }^{4}$, \\ Stefania Rossi ${ }^{5}$, Clara Sina ${ }^{2}$, Claudio Guastella ${ }^{3}$, Roberto Ratiglia ${ }^{1}$ and Paolo Beck-Peccoz \\ Departments of Medical Sciences, ${ }^{1}$ Ophthalmology, ${ }^{2}$ Radiology ${ }^{3}$ Otolaryngology and ${ }^{4}$ Internal Medicine, University of Milan, Fondazione Ospedale \\ Maggiore IRCCS, Milan, Italy, ${ }^{5}$ Pathology Unit, Department of Medicine, Surgery and Dentistry, Ospedale San Paolo, Milan and ${ }^{6}$ Division of Internal \\ Medicine, Ospedale di Fidenza, Parma, Italy \\ (Correspondence should be addressed to P Beck-Peccoz; Email: paolo.beckpeccoz@unimi.it)
}

\begin{abstract}
Introduction: Hyperthyroid Graves' disease (GD) is a B-cell-mediated condition caused by TSH receptor antibodies (TRAb), which decline when GD remits. Anti-CD20 monoclonal antibody rituximab (RTX) induces transient B-cell depletion that may potentially modify the active inflammatory phase of thyroid-associated ophthalmopathy (TAO).

Methods: Nine patients with GD, (seven with active TAO, two with mild lid signs) were studied. The trial was only approved as an open pilot study; thus we compared the effect of RTX therapy to that of i.v. glucocorticoids (IVGC) in 20 consecutive patients. Patients were treated with RTX (1000 mg i.v. twice at 2-week interval) or with IVGC (500 mg i.v. for 16 weeks). TAO was assessed by the clinical activity score (CAS) and severity was classified using NOSPECS (No signs or symptoms; Only signs (lid); Soft tissue involvement; Proptosis, Extraocular muscle involvement; Corneal involvement; Sight loss). Thyroid function and lymphocyte count were measured by standardized methods.

Results: All patients attained peripheral B-cell depletion with the first RTX infusion. Minor side effects were reported in three patients. Thyroid function was not affected by RTX therapy and hyperthyroid patients required therapy with methimazole. After RTX, the changes in the levels of thyroglobulin antibodies, thyroperoxidase antibodies and TRAb were neither significant nor correlated with CD20+ depletion $(P=\mathrm{NS})$. CAS values before RTX were $4.7 \pm 0.5$ and decreased to $1.8 \pm 0.8$ at the end of follow-up $(P<0.0001)$ and more significantly compared with IVGC $(P<0.05)$. Proptosis decreased significantly after RTX both in patients with active TAO (ANOVA; $P<0.0001$ ) and those with lid signs (ANOVA; $P<0.003$ ). The degree of inflammation (class 2) decreased significantly in response to RTX (ANOVA; $P<0.001$ ). Relapse of active TAO was not observed in patients treated with RTX, but occurred in $10 \%$ of those treated with IVGC, who also experienced adverse effects more frequently (45 vs $33 \%$ of patients).

Conclusions: RTX positively affects the clinical course of TAO, independently of either thyroid function or circulating antithyroid antibodies, including TRAb. If our findings are confirmed in large controlled studies, RTX may represent a useful therapeutic tool in patients with active TAO.
\end{abstract}

European Journal of Endocrinology 156 33-40

\section{Introduction}

Hyperthyroidism in Graves' disease (GD) is based on a B-cell driven mechanism leading to sustained production of immunoglobulins $\mathrm{G}$ stimulating the thyroid stimulating hormone (TSH) receptor on the thyrocytes $(1,2)$. This phenomenon emerges in the context of an autoimmune thyroiditis characterized by typical lymphocytic infiltration of the thyroid tissue (3). Serum TSH receptor antibodies (TRAb) correlate well with the clinical course of hyperthyroidism and typically decline when GD is remitting (4).
To date, thyroid-associated ophthalmopathy (TAO) does not have a known pathogenesis. It is known that both Th1 and Th2 cytokine patterns are involved and that the TSH receptor is expressed on orbital preadipogenic fibroblasts and may be a target for immunoglobulin G-stimulated hyperproduction of adipose tissue (5, 6). There is no evidence of pathogenic autoantibodies, TRAb (7) and eye muscle-directed antibodies (8) occurring only at a second pathogenetic step or epiphenomena. Elevated serum TRAb levels have been correlated to the active phase of TAO (9), but this may not imply a role in the disease pathogenesis, since their 
titers have been shown not to vary in relation to the stabilization (10-12) and the duration of the clinical features (M Salvi et al. unpublished observations).

Rituximab (RTX) is a humanized chimeric anti-CD20 $\mathrm{MAB}$ whose variable (antigen-binding) region is derived from a mouse antibody. The binding of RTX to CD20 antigen blocks the activation and differentiation of $\mathrm{B}$ cells, since CD20 protein is expressed on the surface of pre-B and mature B lymphocytes, but not on stem cells, pro-B lymphocytes, and plasma cells $(13,14)$. Therefore, treatment with RTX leads to specific elimination of $\mathrm{B}$ cells without affecting the regeneration of $\mathrm{B}$ cells from stem cells and the production of immunoglobulins by plasma cells.

The rationale of the present study is based on the potential effect of RTX treatment on B-cell-mediated immunity in GD and TAO $(15,16)$. When compared with the natural course of Graves' hyperthyroidism, TAO has a self-limiting evolution with an active phase lasting a relatively limited time (6-18 months) and followed by clinical stabilization. We thought that transient B-cell depletion induced by RTX, which generally lasts 4-6 months, may effectively modify the active inflammatory phase of TAO and its subsequent clinical course.

Here, we report the results of an open study on the treatment with RTX of nine patients with GD and ophthalmopathy. All patients showed a clear clinical improvement of TAO shortly after RTX infusion, but not of hyperthyroidism, with persistence of elevated serum TRAb titers, in spite of peripheral B-cells depletion.

\section{Patients and methods}

\section{Patients}

We have studied nine patients with GD, seven women and two men, aged 31-51 year (mean \pm s.E.M. age
$44.8 \pm 2.1$ ), of whom seven had active TAO and two, with newly diagnosed hyperthyroidism, only mild lid signs. Five patients were smokers, two were ex-smokers and two never smoked. At the time of RTX therapy, four patients were hyperthyroid and untreated; five were euthyroid, two on methimazole (MMI), two in remission after a previous course of MMI, and one patient on L-thyroxine for 12 months after previous thyroidectomy (Table 1). TAO was diagnosed as moderate-severe with CAS of three or greater in six patients, and severe in one patient with CAS of seven and rapid deterioration of visual field and of visual acuity. In two of these patients, clinically active TAO had relapsed 3 and 4 months respectively after previous steroid therapy. Two patients had only lid signs and mild conjunctival inflammation and were treated to test the effect of RTX on Graves' hyperthyroidism. After RTX, eight patients have been studied up to 12 months and one up to 5 months respectively of the follow-up period. Five TAO patients have been studied at 18 months after RTX.

Since we could not carry out a randomized controlled therapeutic trial, as the drug manufacturer only allowed a pilot open study, we decided to compare the effect of RTX therapy with that of i.v. glucocorticoids (IVGC) in a group of 20 consecutive patients, 17 women and three men, aged 30-82 years (mean \pm s.e.m. age $55.4 \pm 2.9$ years), treated according to the standard protocol applied in our center. Twelve patients were smokers, four ex-smokers, and four never smoked. Of these patients, 19 had GD and were euthyroid, 16 on antithyroid therapy, two because of disease remission, and one on L-T4 after thyroidectomy. One patient had euthyroid Graves' ophthalmopathy. All patients had active TAO: three had mild, 13 had moderate, and four had severe disease. All patients were treated with $500 \mathrm{mg}$ of methylprednisolone once a week for 16 weeks and were studied up to 12 months after therapy. IVGC therapy was discontinued at 10 weeks in one patient who

Table 1 Clinical parameters of patients with thyroid-associated ophthalmopathy treated with rituximab.

\begin{tabular}{|c|c|c|c|c|c|c|c|c|c|}
\hline Patient & Sex & Age & Smoking & $\begin{array}{l}\text { Thyroid } \\
\text { status }\end{array}$ & $\begin{array}{c}\text { Thyroid } \\
\text { volume }(\mathrm{ml})\end{array}$ & Therapy & $\begin{array}{l}\text { TAO activity } \\
\text { (CAS) }\end{array}$ & $\begin{array}{l}\text { TAO severity } \\
\text { (NOSPECS) }\end{array}$ & Orbital involvement \\
\hline 1 & $\mathrm{~F}$ & 31 & No & Hyperthyroid & 19.5 & Propranolol $120 \mathrm{mg}$ & 2 & 2а3040 & Fat hypertrophy \\
\hline 2 & $\mathrm{~F}$ & 51 & No & Hyperthyroid & 8.3 & Propranolol $60 \mathrm{mg}$ & 2 & 2a3040 & Normal \\
\hline 3 & $\mathrm{~F}$ & 46 & Yes & Euthyroid & 17.6 & Methimazole $10 \mathrm{mg}$ & 5 & 2b3a4b & $\begin{array}{l}\text { OD: MR, OS, IR } \\
\text { RE: MR, IR } \\
\text { Fat hypertrophy }\end{array}$ \\
\hline 4 & $\mathrm{~F}$ & 47 & No & Euthyroid & 7.2 & - & 5 & $2 a 3 a 4 b$ & OO: MR, IR (OD > OS) \\
\hline 5 & M & 40 & Yes & Hyperthyroid & 68.4 & - & 5 & $2 a 304 a$ & $\begin{array}{l}\text { OS: SR, LR (minimal } \\
\text { enlargement) } \\
\text { OD: LR, SR } \\
\text { Fat hypertrophy }\end{array}$ \\
\hline 6 & $\mathrm{~F}$ & 49 & No & Hyperthyroid & 14.2 & - & 3 & $2 \mathrm{a} 3 \mathrm{a} 40$ & $\begin{array}{l}\text { OD: IR, SR } \\
\text { OS: IR, SR, LR }\end{array}$ \\
\hline 7 & M & 50 & Yes & Euthyroid & & L-T4 125 mcg & 7 & $2 c 304 b$ & OO: all muscles \\
\hline 8 & $\mathrm{~F}$ & 43 & Yes & Euthyroid & 11.5 & - & 4 & $4 b 3040$ & $\begin{array}{l}\text { OD: SR, IR, MR } \\
\text { OS: SR, MR }\end{array}$ \\
\hline 9 & $\mathrm{~F}$ & 54 & Yes & Euthyroid & 13.8 & Methimazole $2.5 \mathrm{mg}$ & 6 & $2 c 3 b 4 b$ & $\begin{array}{l}\text { OO: all muscles } \\
\text { Initial apical crowding }\end{array}$ \\
\hline
\end{tabular}

OD, OS: right, left eye; MR, medial rectus; IR, inferior rectus; SR, superior rectus; LR, lateral rectus; CAS, clinical activity score; NOSPECS, severity according to Werner SC, 1969. 
had acute optic neuropathy and underwent orbital decompression.

Patients were seen in our joint thyroid-eye clinic and at each visit blood was taken for thyroid function tests, serum autoantibody testing, and, in the RTX group, for the study of peripheral lymphocytes. Patients treated with RTX were studied at 4, 8, 12, 16, 20, 30, 50, and 70-75 weeks, while those treated with IVGC were studied at $8,20,30$, and 50 weeks after the first drug infusion (Fig. 1). Based on clinical findings, thyroid ultrasound was also carried out in RTX treated patients to assess goiter changes. The ophthalmological examination included lid fissure and Hertel measurements, color vision, cover test, Hess-Lancaster screen, visual acuity, tonometry, fundus examination, and visual field. Orbital computed tomography (CT) scan was performed in all patients to study the intraorbital tissue components. At the second ophthalmological visit and at each subsequent examination the CAS was calculated (17) in order to monitor the clinical improvement of the patients. The severity was classified according to the NOSPECS score (18).

\section{Therapeutic protocol}

Patients were submitted to treatment with RTX, a chimeric human-mouse MAB (MabThera) kindly provided by Hoffman La Roche, Basel, Switzerland. The study protocol was approved by the ethics committee of the hospital and the patient gave informed consent for the therapy. The recommended therapeutic protocol was the one used for treatment of patients with rheumatoid arthritis and consisted of i.v. infusion of $1000 \mathrm{mg}$ of RTX over approximately $4 \mathrm{~h}$ and $15 \mathrm{~min}$, twice at a 2-week interval. One hour prior to RTX infusion, we administered paracetamol (1 g) and chlorphenamine $(10 \mathrm{mg})$ orally to prevent possible allergic reactions. Patients treated with IVGC underwent 16 weekly infusions of $500 \mathrm{mg} /$ week of methyprednisolone, the last 2 cycles $250 \mathrm{mg} /$ week (Fig. 1).

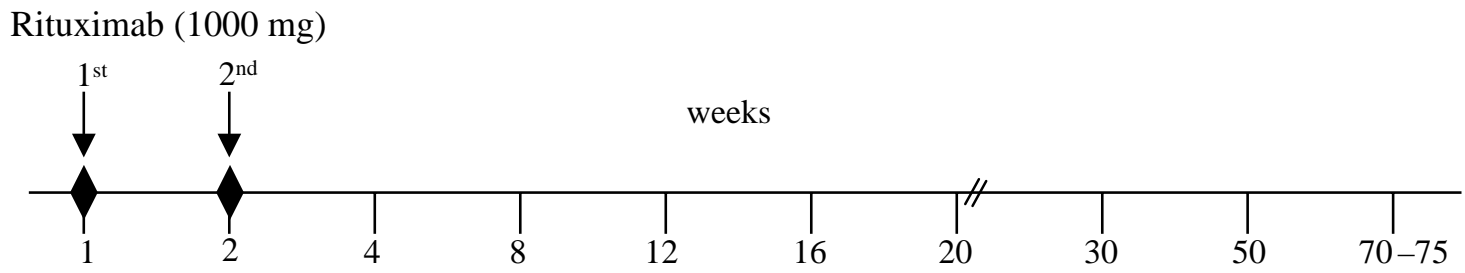

\begin{tabular}{ccccc}
\hline $\begin{array}{c}\text { Patients } \\
\text { treated }\end{array}$ & $\begin{array}{c}\text { N. of patients with adverse } \\
\text { reaction }(\%)\end{array}$ & $\begin{array}{c}\text { Type of adverse } \\
\text { reaction }\end{array}$ & Time & Treatment \\
\hline 9 & $3(33)$ & $\begin{array}{l}\text { Nose and throat itching; } \\
\text { mild temperature elevation }\end{array}$ & $1^{\text {st } \text { infusion }}$ & $\begin{array}{c}\text { Hydrocortisone } \\
100 \text { mg i.v. }\end{array}$ \\
\hline
\end{tabular}

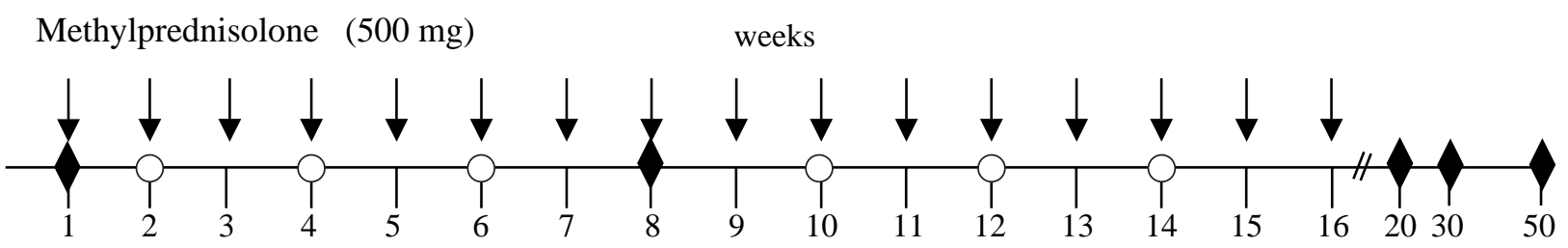

\begin{tabular}{cclll}
\hline $\begin{array}{c}\text { Patients } \\
\text { treated }\end{array}$ & $\begin{array}{c}\text { N. of patients with adverse } \\
\text { reaction }(\%)\end{array}$ & $\begin{array}{c}\text { Type of adverse } \\
\text { reaction }\end{array}$ & Time & Treatment \\
\hline 20 & $9(45)$ & $\begin{array}{l}\text { Flushing } \\
\text { Insomnia } \\
\text { Dyspepsia } \\
\text { Hyperglycemia } \\
\text { Serum aminotransferases or } \\
\text { gamma-GT increase }\end{array}$ & $\begin{array}{l}\text { Throughout } \\
\text { treatment }\end{array}$ & $\begin{array}{l}\text { after infusion } \\
\text { Anti-acids } \\
\text { Metformin } \\
\text { Diet }\end{array}$ \\
& & & Dine \\
\hline
\end{tabular}

Figure 1 Modalities of rituximab and methylprednisolone administration in patients with active thyroid-associated ophthalmopathy and prevalence of the adverse reactions to treatments. Biochemical and ophthalmological assessment; Obiochemical assessment; $\downarrow$ i.v. administration. 


\section{Biochemical and immunological testing}

Serum TSH and FT4 concentrations and antithyroglobulin antibodies $(\mathrm{TgAb})$, and antithyroperoxidase antibodies (TPOAb) were measured using the AutoDELFIA technique (Perkin-Elmer-Life Sciences, Wallac Oy, Turku, Finland). Serum TSH receptor antibodies (TRAb), detected as TSH binding inhibitory immunoglobulins, were measured using a 2nd generation TRAK human lumitest (B R A H M S, AG, Henningsdorf/Berlin, Germany).

\section{Cytofluorimetric analysis}

In patients treated with RTX, we looked at the pattern of peripheral blood lymphocytes before therapy and throughout the study period. Moreover, in one patient we had the opportunity to analyze the lymphocytes subpopulations within the thyroid tissue, at thyroidectomy, in a lymph node of the neck, removed during surgery, and within the orbital fat and connective tissue, at decompression (15). We have studied the standard immunophenotypic panel $(\mathrm{CD} 3+, \mathrm{CD} 3+4+, \mathrm{CD} 3+$ $8+, \mathrm{CD} 3+\mathrm{DR}+, \mathrm{CD} 20+, \mathrm{CD} 19+5+, \mathrm{CD} 56+16+$ 3 ) on aliquots of around $10^{5}$ lymphocytes, submitted to standard triple staining procedures in order to carry out immunogating with CD45, and we analyzed pairs of monoclonal antibodies to subpopulations of T, B, and NK cells, then processed in the flowcytometer (BD Facsan, Cell-quest software, Becton-Dickinson, San José, CA, USA).

\section{Statistical analysis}

The changes of serum antibody levels and of CAS and proptosis values in response to RTX therapy and by comparison with IVGC treatment were analyzed by repeated measures ANOVA. NOSPECS class 2 and motility scores were tested by Wilcoxon. Correlations were analyzed by non-parametric Spearman's rank test.

\section{Results}

\section{Effects of RTX: B-cell depletion and adverse reactions}

All patients attained peripheral B-cell depletion with the first RTX infusion (Fig. 2). In all nine patients, the decrease of peripheral CD20 + count in response to RTX was significant (ANOVA; $P<0.0001$ ). One patient showed no CD20+ lymphocytes after the first RTX infusion but persistence of $2.8-4.9 \%$ CD $19+$ lymphocytes throughout the study period. Peripheral B-cell depletion lasted 5 months in five patients and 4 months in three patients, while one patient is still B-cell depleted at 5 months of follow-up. All patients well tolerated RTX and only minor side effects were reported in three patients during the first infusion (Fig. 1).

\section{Effects of RTX on thyroid function}

Thyroid function was not affected by RTX therapy. The two patients with GD and only lid signs did not show
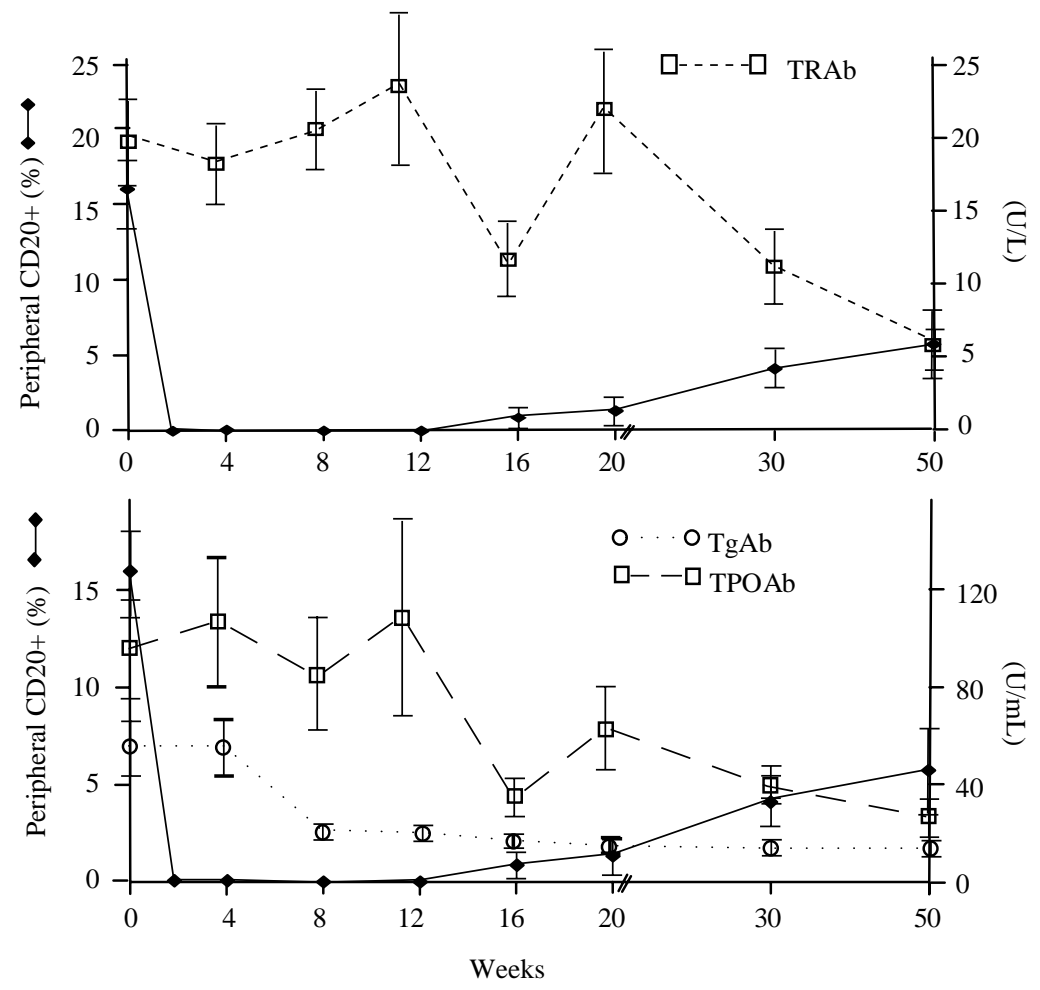

Figure 2 Changes of serum thyroid autoantibodies levels in relation to peripheral depletion of CD20 + lymphocytes after treatment with rituximab in patients with active thyroid-associated ophthalmopathy. TRAb, TSH receptor antibodies; TPOAb, thyroperoxidase antibodies; $\mathrm{TgAb}$, thyroglobulin antibodies. Values are indicated as mean \pm S.E.M. 
improvement of hyperthyroidism during RTX-induced B-cell depletion. One of them was subclinically hyperthyroid and eventually became euthyroid at 8 months after RTX. Among TAO patients, the two, who were euthyroid because of disease remission before RTX, remained so without requiring therapy throughout the study period. In the three patients with untreated disease, hyperthyroidism did not improve and therefore MMI was started at 6-12 weeks during RTX-induced B-cell depletion. One patient on MMI, in whom the drug was stopped because of elevation of serum TSH suggestive for disease remission, rapidly showed a relapse of hyperthyroidism, while persisting peripheral B-cell depletion.

\section{Effects of RTX on thyroid autoimmunity}

After RTX, the changes of levels of TgAb, TPOAb, and TRAb were not significant (ANOVA; $P=N S$ ) and were not correlated to CD20 + lymphocytes depletion (Spearman; $P=$ NS; Fig. 2). Mean (土s.E.M.) serum TgAb levels were $52 \pm 24.6 \mathrm{U} / \mathrm{L}$ before therapy and $13.4 \pm 4.6 \mathrm{U} / \mathrm{L}$ at the end of the follow-up period and their decrease showed a slightly significant negative correlation with time (Spearman; $R=-0.27, P<0.04$ ), likely to be related to the attainment of euthyroidism after antithyroid treatment. Serum TPOAb were detectable in five out of the nine patients and their titers slightly increased in two at 2-4 weeks of treatment. Serum TRAb levels were 19.3 \pm 6.7 U/L before treatment and 11.5 $\pm 9.2 \mathrm{U} / \mathrm{L} 30$ weeks after RTX (ANOVA; $P=$ NS) (Table 2) and their changes did not correlate with either the phase of depletion or of return of CD20 lymphocytes in the periphery (Spearman; $P=N S)$. Serum TRAb levels did not even decrease in the patient on L-thyroxine who underwent total thyroidectomy a year before. Serum TRAb levels decreased further at 75 weeks of follow-up with a slightly significant negative correlation with time (Spearman; $R=-0.33$, $P<0.01$ ), when all patients reached stable euthyroidism. In fact two patients, one euthyroid and one hyperthyroid not treated with MMI, who had slightly increased basal serum TRAb levels $(<5 \mathrm{U} / \mathrm{L})$, after RTX therapy showed progressive normalization of serum TRAb levels in relation to remission of Graves' hyperthyroidism. In the patient who relapsed shortly after discontinuation of MMI, while still having B-cell depletion, serum TRAb levels showed a sudden rise preceding hyperthyroidism, as commonly observed in GD patients.

\section{Effect of RTX on clinical TAO}

In all the patients treated with RTX, we have observed a definite clinical improvement of TAO, including the one at 5 months of the follow-up period. Data were statistically analyzed at 30 weeks of follow-up and are shown in Table 3. The mean ( \pm s.E.m.) CAS value before therapy was $4.7 \pm 0.5$ and decreased to $1.8 \pm 0.8$ (ANOVA, $P<0.0001$ ). A decrease of CAS to $<3$ was consistently observed within a month of treatment with RTX. We also studied the effect of RTX therapy on disease severity by separating out the changes of parameters like soft tissue inflammation (NOSPECS, class 2), proptosis (NOSPECS, class 3), and motility involvement (NOSPECS, Class 4). Proptosis decreased significantly after RTX in both patients with active TAO (ANOVA; $P<0.0001$ ) and in those with GD and lid signs (ANOVA; $P<0.003$ ). The degree of inflammation (class 2) decreased significantly in response to RTX (ANOVA; $P<0.001$ ) as well as the degree of motility impairment (Wilcoxon; $P<0.05$ ), as also shown by the Gorman score in Table 4 (19). Interestingly, the clinical picture has progressively stabilized after treatment and we have not observed relapse of active TAO in any of the patients both at the time of B-cell return into the peripheral blood, generally at 5-6 months after RTX treatment, and in the subsequent 5-7 months of followup, in those who have completed it.

\section{Comparison of the effects of RTX and IVGC in TAO patients}

Mean ( \pm s.E.M.) serum TRAb levels before IVGC were $16.3 \pm 4.9$ and $9.3 \pm 3.6 \mathrm{U} / \mathrm{L}$ after therapy (ANOVA; $P=\mathrm{NS}$ ) (Table 2). The changes were not different compared with RTX therapy (ANOVA; $P=\mathrm{NS}$ ) at 30 weeks.

In the group of 20 TAO patients treated with IVGC, mean (土s.E.M.). CAS value significantly decreased from $4.1 \pm 0.3$ before to $2.0 \pm 0.4$ at 30 weeks after therapy (ANOVA; $P<0.0001$ ). When compared with the group of TAO (Table 3) patients treated with RTX, we found a significant difference (ANOVA; $P<0.05)$. Patients after

Table 2 Mean serum TRAb levels (U/L) at baseline and after therapy in patients treated with rituximab or i.v. methylprednisolone.

\begin{tabular}{|c|c|c|c|}
\hline Weeks from therapy & Rituximab therapy (no. 7) & ANOVA & $\begin{array}{l}\text { Methylprednisolone therapy } \\
\text { (no. 20) }\end{array}$ \\
\hline $\begin{array}{l}0 \\
8 \\
20 \\
30 \\
\text { ANOVA }\end{array}$ & $\begin{array}{c}19.3 \pm 6.7^{*} \\
18.5 \pm 9.3 \\
14.8 \pm 7.0 \\
11.5 \pm 9.2 \\
P=\text { NS }\end{array}$ & Rituximab vs methylprednisolone $P=$ NS & $\begin{array}{c}16.3 \pm 4.6 \\
11.4 \pm 4.2 \\
8.9 \pm 4.1 \\
9.3 \pm 3.6 \\
P=\mathrm{NS}\end{array}$ \\
\hline
\end{tabular}

${ }^{*}$ Mean \pm S.E.M. 
Table 3 Comparison between rituximab and i.v. methylprednisolone therapy in patients with Graves' disease (GD) and associated ophthalmopathy (TAO).

\begin{tabular}{|c|c|c|c|c|c|c|}
\hline Patients (no.)/therapy & Weeks & Proptosis & $\begin{array}{l}\boldsymbol{P}(\text { ANOVA } \\
\text { vs week 0) }\end{array}$ & CAS & $\begin{array}{l}\boldsymbol{P}(\text { ANOVA } \\
\text { vs week 0) }\end{array}$ & $\begin{array}{c}\text { Class } 2 \\
\text { (Wilcoxon vs } \\
\text { week 0) }\end{array}$ \\
\hline \multirow[t]{5}{*}{ GD (no. 2)/rituximab } & 0 & $19.0 \pm 0.7^{*}$ & - & - & - & - \\
\hline & 8 & $18.0 \pm 1.2$ & NS & - & - & - \\
\hline & 20 & $17.7 \pm 1.1$ & NS & - & - & - \\
\hline & 30 & $17.3 \pm 0.9$ & $<0.006$ & - & - & - \\
\hline & $P$ (ANOVA) & $<0.003$ vs TAO $<0.015$ & & & & - \\
\hline \multirow[t]{5}{*}{ TAO (no. 7)/rituximab } & 0 & $22.4 \pm 0.5$ & - & $4.7 \pm 0.5$ & - & - \\
\hline & 8 & $21.8 \pm 0.6$ & $<0.02$ & $2.7 \pm 0.3$ & $<0.01$ & NS \\
\hline & 20 & $21.3 \pm 0.6$ & $<0.02$ & $2.0 \pm 0.4$ & $<0.0001$ & $<0.03$ \\
\hline & 30 & $20.9 \pm 0.6$ & $<0.005$ & $1.8 \pm 0.8$ & $<0.004$ & $<0.04$ \\
\hline & $P$ (ANOVA) & $<0.0001$ & & $<0.0001$ vs Methylpred. $<0.05$ & & $<0.001$ \\
\hline \multirow[t]{5}{*}{ TAO (no. 20)/methylpred. } & 0 & $22.6 \pm 0.6$ & - & $4.1 \pm 0.3$ & - & - \\
\hline & 8 & $22.3 \pm 0.6$ & NS & $2.6 \pm 0.3$ & $<0.001$ & NS \\
\hline & 20 & $21.9 \pm 0.6$ & $<0.03$ & $2.1 \pm 0.3$ & $<0.0001$ & $<0.001$ \\
\hline & 30 & $22.1 \pm 0.6$ & NS & $2.0 \pm 0.4$ & $<0.0001$ & $<0.003$ \\
\hline & $P$ (ANOVA) & $<0.014$ vs Rituximab NS & & $<0.0001$ & & vs Rituximab NS \\
\hline
\end{tabular}

${ }^{*}$ Mean + S.E.M.

IVGC usually reported amelioration of symptoms and were assessed to have a reduction of the CAS at 6-8 weeks, relatively later compared to RTX. Proptosis significantly improved after IVGC (ANOVA; $P<0.02$ ), and not differently from RTX therapy (ANOVA; $P=$ NS). The degree of Class 2 signs also decreased significantly after IVGC (Wilcoxon; $P<0.003$ ). These results did not differ from those observed after RTX (ANOVA; $P=$ NS).

Adverse effects were more frequent after IVGC (45 vs $33 \%$ of patients) and of greater clinical relevance (Fig. 1). While all the patients responded to RTX (100\%), as shown by the significant decrease in the CAS, NOSPECS class 2 and proptosis values, four of the patients did not respond to IVGC and one underwent acute orbital decompression for optic neuropathy, therefore making up to a total of $75 \%$ of patients responders. Furthermore, an additional two patients (10\%) showed relapse of active TAO at 6-8 weeks after IVGC withdrawal.

\section{Discussion}

This is the first pilot open study on the use of RTX for the treatment of active TAO. The use of RTX in GD and TAO was approved by the scientific board of the drug manufacturing company only as a phase 3 pilot open study. For this reason we were only able to study, as controls, a group of consecutive patients treated with IVGC for active TAO. This allowed us to validate the data on the therapeutic effect of RTX by comparison with what is considered the standard therapy for this disease (20-22). The main finding is that RTX does positively affect the clinical course of TAO, independently of either the thyroid function or the pattern of circulating antithyroid antibodies and in particular of the TRAb.

Response to therapy correlated well with peripheral $\mathrm{CD} 20+$ depletion, which was attained in all patients already with the first RTX dose. One patient showed no
CD20 + cells after RTX treatment, but persistence of about 3-5\% CD 19+ cells, of which about $90 \%$ were co-expressing CD $19+5+$, characteristic of clones committed to production of autoantibodies (23). We have also previously observed an increased prevalence of CD $19+5+$ (about 50\%) in the intrathyroidal lymphocytes of the patient who underwent thyroidectomy at the time of initial peripheral B-cell return, 5 months after RTX treatment (15). This lymphocyte subset represents the bulk of cells that reconstitute peripheral blood during the early repletion period (24). Data from RTX therapy studies conducted in human systemic lupus erythematosus show that complete B-cell depletion (arbitrarily defined as depletion to $<1 \%$ of the total peripheral blood cells) is not necessary for clinical response (25).

Interestingly, B-cell depletion did not cause changes in circulating serum thyroid autoantibodies. This might be due to persistence of plasma cells, which do not express CD20 and may continue to produce antibodies $(13,14)$, although they would only be measured in the circulation for as long as $4-6$ weeks, if one considers that the half life of human $\operatorname{IgG}$ is approximately 3 weeks (26). Our data rather suggest that autoantibodies may not be produced by peripheral B lymphocytes, but perhaps by lymphocytes in the thyroid or in other

Table 4 Diplopia according to the Gorman score in patients with active TAO at baseline and after therapy in patients treated with RTX.

\begin{tabular}{llll} 
Patient & Before therapy & $\mathbf{8}$ Weeks & 30 Weeks \\
\hline 3 & Inconstant & Inconstant & Constant \\
4 & Inconstant & Inconstant & Intermittent \\
5 & Inconstant & Inconstant & Intermittent \\
6 & Inconstant & Absent & Absent \\
7 & Constant & Inconstant & Inconstant \\
8 & Inconstant & Absent & Absent \\
9 & Constant & Inconstant & Inconstant \\
\hline
\end{tabular}


lymphoid organs such as the bone marrow or the spleen (27). Persistence of small germinal centers was in fact shown in thyroid surgical specimens from thyroidectomy of one of our patients carried out at the time of initial B-cell return (15).

Discrepancies between a positive clinical response and an effect on circulating autoantibodies after RTX have been observed in systemic autoimmune diseases such as lupus (28) and rheumatoid arthritis (29). In our study, the findings argue against a pathogenic role of TRAb in TAO (30). Serum TRAb levels declined in relation to time only when disease remission occurred, spontaneously in one patient and as a consequence of MMI therapy in the others $(11,31)$. The fact that RTX treatment had no effect on hyperthyroidism in GD patients is probably consequent to its absent effect on TRAb production. Throughout the B-cell depletion period we needed to either commence or maintain treatment with MMI, which was administered by a standard dose titration protocol until stable euthyroidism in five of our hyperthyroid patients. Progression to euthyroidism without therapy was observed only in one patient who had relatively low serum TRAb titers at the time of RTX therapy.

Although our findings were not derived form a controlled and randomized study, the improvement of the clinical activity of TAO after RTX was more pronounced than that observed after IVGC and seemed to appear relatively earlier. Interestingly, the CAS continued to decline in patients treated with RTX even after the first 5 months of follow-up, when B-cells returned, whereas the same was not observed in patients after IVGC, some of whom showed, indeed, relapse of active TAO. RTX therapy was at least as effective as IVGC in modifying disease severity, as shown by the significant improvement of proptosis and soft tissue inflammation. While RTX treatment seemed also effective in reducing motility impairment, this data has to be confirmed after comparison with IVGC therapy and we could not do this in the present study. Interestingly, we reported some differences in the rate of adverse effects more frequent and bothersome for patients during IVGC than RTX. RTX did not expose patients to opportunistic infections and did not alter their perception of being in good health. Greater differences were observed in the rate of the therapeutic response to RTX (100 vs 75\%) and, more interestingly, in that of the relapse of active TAO, which was absent at any time during follow-up even after B-cell return in peripheral blood.

Although our study is preliminary, since we have treated a relatively small number of patients, we suggest that while steroids may act more as anti-inflammatory agents (11, 32), RTX may affect TAO as a true immunosuppressor. The 4-5 month duration of B-cell depletion after RTX is probably significant in switching off the autoimmune reactions inducing the active phase of TAO, perhaps by altering the cytokine milieu in the orbit $(30,33,34)$. We have produced evidence from the histopathological studies on one of our patients after RTX treatment of the absence of lymphocytic infiltration in the orbit, but not in other tissues like the thyroid or a neck lymph node (15). We can then speculate that RTX therapy in patients with active TAO induces depletion of lymphocytes in the orbit without affecting the intrathyroidal lymphocytic population. Furthermore, since in that patient both $\mathrm{B}$ and $\mathrm{T}$ lymphocytes were not found in orbital tissues, we hypothesize that perhaps the mechanism by which RTX exerts its therapeutic action in TAO is the depletion of antigen presenting $\mathrm{B}$ cells as initiators of orbital autoimmune reactions $(30,35)$. More tissue analysis is needed to confirm this hypothesis, also performed on specimens obtained in patients undergoing acute orbital decompression for optic neuropathy. Although our findings are derived from a preliminary and not controlled study, we believe that the observed improvement of active TAO after RTX therapy is not due to spontaneous variations of the natural course of the disease for three reasons. First, the decrease of the NOSPECS and the CAS scores are evident within 4-6 weeks from RTX therapy, earlier than the average response time observed after steroids in the patients of the group of controls. Second, two of the patients were treated successfully with RTX after having not responded to IVGC and presenting a relapse of TAO after steroid withdrawal $(15,36)$. Third, none of the nine patients has shown relapse of eye inflammation after RTX, despite the fact that the drug had no effect on hyperthyroidism and TRAb.

In conclusion, if our findings are confirmed in larger and controlled studies, we believe that RTX may represent a useful therapeutic tool in patients with active TAO and may be more effective than the standard therapy with IVGC. Besides being safe, RTX is better tolerated by patients who also seem to prefer its therapeutic protocol, such as the one applied in this study.

\section{Acknowledgements}

We wish to thank Dr Martino Introna of the Division of Haematology, Ospedali Riuniti, Bergamo, Italy for fruitful discussion on the rationale of the work and Dr Tim Shaw of Hoffman La Roche, England for providing us with Mab Thera. This work is supported in part by MURST, Roma and by Fondazione Ospedale Policlinico, IRCCS, Milano, Italy.

\section{References}

1 Zakarija M \& McKenzie JM. The spectrum and significance of autoantibodies reacting with the thyrotropin receptor. Endocrinology and Metabolism Clinics of North America $1987 \quad 16$ 343-363.

2 Rees Smith B, McLachlan SM \& Furmaniak J. Autoantibodies to the thyrotropin receptor. Endocrine Review 19888 106-121.

3 Segundo C, Rodriguez C, Garcia-Poley A, Aguilar M, Gavilan I, Bellas C \& Brieva JA. Thyroid-infiltrating B lymphocytes in Graves' disease are related to marginal zone and memory B cell compartments. Thyroid 200111 525-530. 
4 Michelangeli V, Poon C, Taft J, Newnham H, Topliss D \& Colman P. The prognostic value of thyrotropin receptor antibody measurement in the early stages of treatment of Graves' disease with antithyroid drugs. Thyroid 19988 119-124.

5 Bahn RS. Clinical review 157: pathophysiology of Graves' ophthalmopathy: the cycle of disease. Journal of Clinical Endocrinology and Metabolism 200388 1939-1946.

6 Valyasevi RW, Harteneck DA, Dutton CM \& Bahn RS. Stimulation of adipogenesis, peroxisome proliferator-activated receptor-gamma (PPARgamma), and thyrotropin receptor by PPARgamma agonist in human orbital preadipocyte fibroblasts. Journal of Clinical Endocrinology and Metabolism 200287 2352-2358.

7 Cao HJ, Wang HS, Zhang Y, Lin HY, Phipps RP \& Smith TJ. Activation of human orbital fibroblasts through CD40 engagement results in a dramatic induction of hyaluronan synthesis and prostaglandin endoperoxide $\mathrm{H}$ synthase-2 expression: insights into potential pathogenic mechanisms of thyroid-associated ophthalmopathy. Journal of Biological Chemistry $199827329615-29625$.

8 Mikozami T, Salvi M \& Wall JR. Eye muscle antibodies in Graves' ophthalmopathy: pathogenic or secondary epiphenomenon? Journal of Endocrinological Investigation 200427221.

9 Gerding MN, van der Meer JW, Broenink M, Bakker O, Wiersinga WM \& Prummel MF. Association of thyrotrophin receptor antibodies with the clinical features of Graves' ophthalmopathy. Clinical Endocrinology 200052 267-271.

10 De Bellis A, Bizzarro A, Conte M, Solimeno C, Perrino S, Sansone D, Guaglione M, Wall JR \& Bellastella A. Relationship between longitudinal behaviour of some markers of eye autoimmunity and changes in ocular findings in patients with Graves' ophthalmopathy receiving corticosteroid therapy. Clinical Endocrinology $2003 \mathbf{5 9} 388-395$.

11 Kubota S, Ohye H, Nishihara E, Kudo T, Ito M, Fukata S, Amino N, Kuma K \& Miyauchi A. Effect of high dose methylprednisolone pulse therapy followed by oral prednisolone administration on the production of anti-TSH receptor antibodies and clinical outcome in Graves' disease. Endocrine Journal 200552 735-741.

12 Eckstein AK, Plicht M, Hildegard L, Neuhauser M, Mann K, Lederbogen S, Heckmann C, Esser J \& Morgenthaler NG. TSHreceptor autoantibodies are independent risk farctors for Graves' ophthalmopathy and help to predict severity and outcome of the disease. Journal of Clinical Endocrinology and Metabolism 200691 3464-3470.

13 Tsokos GC. B cells be gone - B-cell depletion in the treatment of rheumatoid arthritis. New England Journal of Medicine $20043 \mathbf{3 0}$ 2546-2548.

14 Pescovitz MD. Rituximab, an anti-CD20 monoclonal antibody: history and mechanism of action. American Journal of Transplantation $2006 \mathbf{6} 859-866$.

15 Salvi M, Vannucchi G, Campi I, Rossi S, Bonara P, Sbrozzi F, Guastella C, Avignone S, Pirola G, Ratiglia R \& Beck-Peccoz P. Efficacy of rituximab treatment for thyroid-associated ophthalmopathy as a result of intraorbital B-cell depletion in one patient unresponsive to steroid immunosuppression. European Journal of Endocrinology $2006 \mathbf{1 5 4} 511-517$.

16 El Fassi D, Nielsen CH, Hasselbalch HC \& Hegedus L. The rationale for B lymphocyte depletion in Graves' disease. Monoclonal antiCD20 antibody therapy as a novel treatment option. European Journal of Endocrinology 2006154 623-632.

17 Mourits MP, Prummel MF, Wiersinga WM \& Koorneef L. Clinical activity score as a guide in the management of patients with Graves' ophthalmopathy. Clinical Endocrinology 1997 47 9-14.

18 Werner SC. Classification of the eye changes of Graves' disease. Journal of Clinical Endocrinology and Metabolism 196929 982-984.

19 Gorman CA. The measurement of change in Graves' ophthalmopathy. Thyroid $1998 \mathbf{8}$ 539-543.

20 Hiromatsu Y, Tanaka K, Sato M, Kuroki T, Nonaka K, Kojima K, Nishimura H, Noshida H \& Kaise N. Intravenous methylprednisolone pulse therapy for Graves' ophthalmopathy. Endocrine Journal $1993 \mathbf{4 0} 63-72$.
21 Marcocci C, Bartalena L, Tanda ML, Manetti L, Dell'Unto E, Rocchi R, Barbesino G, Mazzi B, Bartolomei MP, Lepri P, Cartei F \& Nardi M. Pinchera A comparison of the effectiveness and tolerability of intravenous or oral glucocorticoids associated with orbital radiotherapy in the management of severe Graves' ophthalmopathy: results of a prospective, single-blind, randomized study. Journal of Clinical Endocrinology and Metabolism 2001 86 3562-3567.

22 Kahaly GJ, Pitz S, Hommel G \& Dittmar M. Randomized, single blind trial of intravenous versus oral steroid monotherapy in Graves' orbitopathy. Journal of Clinical Endocrinology and Metabolism 2005 90 5234-5240.

23 Davidson A \& Diamond B. Autoimmune diseases. New England Journal of Medicine 2001345 340-350.

24 Sidner RA, Book BK, Agarwal A, Bearden CM, Vieira CA \& Pescovitz MD. In vivo human B-cell subset recovery after in vivo depletion with rituximab, anti-human CD20 monoclonal antibody. Human Antibodies 200413 55-62.

25 Anolik JH, Barnard J, Cappione A, Pugh-Bernard AE, Felgar RE, Looney RJ \& Sanz I. Rituximab improves peripheral B cell abnormalities in human systemic lupus erythematosus. Arthritis E Rheumatism 200450 3580-3590.

26 Male D, Cooke A, Owen M, Trowsdale J \& Champion B. Antigen receptor molecules Advanced Immunology, pp. 2.1-2.2, London: Mosby, 1996.

27 Armengol MP, Juan M, Lucas-Martin A, Fernandez-Figueras MT, Jaraquemada D, Gallart T \& Pujol-Borrel R. Thyroid autoimmune disease: demonstration of thyroid antigen-specific $B$ cells and recombination-activating gene expression in chemokinecontaining active intrathyroidal germinal centers. American Journal of Pathology 2001159 861-873.

28 Anolik JH, Campbell D, Felgar RE, Rosenblatt J, Young F, Sanz I \& Looney RJ. B lymphocyte depletion in the treatment of systemic lupus erythematosus. Arthritis and Rheumatism, 2002 (Suppl 9) S717 (Abstract).

29 Edwards JC, Szczepanski L, Szechinski J, Filipowicz-Sosnowska A, Emery P, Close DR, Stevens RM \& Shaw T. Efficacy of B-celltargeted therapy with rituximab in patients with rheumatoid arthritis. New England Journal of Medicine $20043502572-2581$.

30 Drexhage HA. Are there more than antibodies to the thryoidstimulating hormone receptor that meet the eye in Graves' disease? Endocrinology 2006 147 9-12.

31 Chiovato L, Latrofa F, Braverman LE, Pacini F, Capezzone M, Masserini L, Grasso L \& Pinchera A. Disappearance of humoral thyroid autoimmunity after complete removal of thyroid antigens. Annals of Internal Medicine 2003139 346-351.

32 Rhen T \& Cidlowski JA. Antiinflammatory action of glucocorticoids - new mechanisms for old drugs. New England Journal of Medicine 2005353 1711-1723.

33 Salvi M, Pedrazzoni M, Girasole G, Giuliani N, Minelli R, Wall JR \& Roti E. Serum concentrations of proinflammatory cytokines in Graves' disease: effect of treatment, thyroid function, ophthalmopathy and cygarette smoking. European Journal of Endocrinology 2000143 197-202.

34 Han R \& Smith TJ. T helper type 1 and type 2 cytokines exert divergent influence on the induction of prostaglandin E2 and hyaluronan synthesis by interleukin-1 beta in orbital fibroblasts: implications for the pathogenesis of thyroid-associated ophthalmopathy. Endocrinology 2006 147 13-19.

35 Rodriguez-Pinto D. B cells as antigen presenting cells. Cellular Immunology 2005238 67-75.

36 El Fassi D, Nielsen CH, Hasselbalch HC \& Hegedus L. Treatmentresistant severe, active Graves' ophthalmopathy successfully treated with B lymphocyte depletion. Thyroid 2006 16 709-710 (Letter).

Received 27 September 2006

Accepted 31 October 2006 